\title{
Fundamental flame spread and toxicity evaluation of fire retarded polymers
}

\author{
MATHIEU SUZANNE ${ }^{1,2}$, SEBASTIAN UKLEJA ${ }^{1,3}$, MICHAEL DELICHATSIOS $^{1}$, JIANPING \\ ZHANG $^{1}$ and BJORN KARLSSON ${ }^{4}$ \\ ${ }^{1}$ University of Ulster, Shore Road, Newtownabbey, BT37 OQB, UK \\ ${ }^{2}$ Central Laboratory of Police Prefecture, 39bis rue de Dantzig, 75015, Paris, France \\ ${ }^{3}$ Centrum Techniki Okretowej S.A., Ship Design and Research Centre, Szczecinska 65, 80-392, \\ Gdansk, Poland \\ ${ }^{4}$ University of Iceland, Hjardarhagi 2-6, 101 Reykjavik, Iceland
}

\begin{abstract}
A simple method is developed for characterizing the fire performance and toxicity of polymers using basically three but up to five parameters if necessary. The first parameter is related to fire spread and growth (corresponding to UL-94 and the FIGRA of SBI), the second parameter is the smoke yield (corresponding to the SMOGRA of SBI), the third parameter is the inefficiency of combustion (related to unburned hydrocarbon compounds and their toxicity as verified by tube furnace measurements), the fourth parameter is the mass of residue remaining and the fifth parameter is a heat release parameter for thermally thin conditions (the maximum mass loss rate in TGA multiplied by the effective heat of combustion deduced from the Cone Calorimeter tests). The developed methodology was used to compare brominated and halogen free fire retardants in formulations of PBT, PA66, PPE/HIPS and PC/ABS. It is confirmed that the studied environmentally friendly alternatives to brominated fire retardants offer comparable fire performance with lower toxicity.
\end{abstract}

KEYWORDS: toxicity, flame spread, heat release rate, fire retardants

\section{INTRODUCTION}

Manufacturers of polymers or flame retardants are constantly looking for improvements in their engineered formulations. In the present paper, the authors do not consider cost, economic or mechanical aspects of the use of flame retardants but only their influence on fire behaviour of the composite polymer. Best material formulations would be those creating the lowest possible threat to people and property when the material is exposed to a thermal stress or, later, when it is burning. Regarding people safety, the pyrolysis or burning material should allow a safe evacuation. Consequently, the material should be difficult to ignite, should not allow flame spread, should not produce toxic gases to prevent any human incapacitation and, finally, should not produce excessive smoke which decreases visibility. Regarding property protection, the intensity of the fire should be reduced as much as possible.

Flame retardants or intumescent paints are consequently commonly used to prevent or delay the ignition of polymers and to reduce the intensity of the fire. Unfortunately, they may also introduce new hazards such as an increase in the toxicity of combustion gases or in smoke production. Moreover, they are known to create over longer periods, owing to disposal, environmental and toxicological hazards as it was reported for brominated flame retardants (BrFRs). Therefore, a balance has to be found between the efficiency of the FR to reduce fire risks and threats and its toxicity and environmental effects.

Many standard tests exist worldwide to assess the fire behaviour or toxicity of materials and, as a matter of consequence, the efficiency of fire retardants (FRs). The aim of this paper is not to provide an exhaustive list and analysis of these tests, which is why only few of them will be mentioned. The test most commonly used in electronic domain is, for instance, the UL-94. It consists in exposing a strip of material in a vertical or horizontal position to a $50 \mathrm{~W}$ flame for twenty seconds (two times ten seconds exposure). This test is supposed to reproduce an exposure of the end-use material to a small flame occurring after a small electric fault. This test can be seen as an ignition assessment followed by a flame spread in laminar conditions without involving any toxicity effects. Furthermore, this test, like many others, ranks materials in different groups but does not allow any differentiation of material behaviour inside a given rank (e.g. inside V0 rated materials). The determination of toxic gases evolved during a fire is a long and 
cumbersome process [1] involving the calibration and use of FTIR or other analytical methods. Moreover the transposition of data obtained at small scale to bigger scale is difficult.

\section{MATERIAL FLAMMABILITY - TEST METHODS AND MATERIAL RANKING}

In the construction industry, some testing and ranking systems for the reaction-to-fire behaviour of building products have been based on test methods which give as output certain rating terms or arbitrary numbers. As an example, such a test method may report a "burnt length" at a given time, or the time until the flame has reached a given length. Such numbers have a very weak or uncertain link to material properties and the dominant physical processes involved. Therefore, they cannot be used for rational classification nor for design calculations. Nonetheless, such test methods have been used, in conjunction with empiricism, to rank materials, but this ranking has a questionable basis.

A much more rational way to develop test methods and test evaluations, whether it is for the construction industry or the aircraft industry, would be to follow the methodology of performance-based testing. Such methods have been discussed in the literature for a number of decades. The CIB (Conseil International du Bâtiment) has for over two decades been working with the performance concept in building design. In a publication from 1982, CIB Working Commission W060 discusses a number of criteria for performance test methods [2]. These criteria can be summarised as follows:

- Conditions of test under which the behaviour of the article is being assessed must be either realistic in relation to the expected conditions of use or related to them in some known way.

- There needs to be a clear scientific basis for relating the results of performance testing under simplified conditions to conditions in practice.

- It is important to consider - and to reconsider - whether the method will be suitable for predicting the behaviour of the product under real conditions of use.

The report [2] also states that although it may theoretically be desirable that a performance-based test method should be independent of the material or construction tested, it is difficult to respect this principle in all cases. It further mentions that the method should ideally be simple but that simplification should not go so far that the method fails to provide a reasonable simulation of conditions of use.

Many other researchers have discussed and further developed the concept of performance-based test methods, for example in [3] and [4]. Before any performance-based test method can be devised, the details behind the testing philosophy must be developed. Specifically, in order to devise a rational ranking system for the flammability of products, which to some extent reflects the hazards encountered in an end-use scenario, one must

1. Define one or more end-use scenarios (aircraft hull (long or short), large room, small room, ignition source, openings, etc) and develop a standardized test for that purpose. The ISO Room Corner test [5] has gained status in a number of countries as a reference scenario for material flammability with regard to materials used in the building industry, but no such recognized end-use scenario exists for interior aircraft materials.

2. Define one or more limit states or critical conditions (e.g. time until a certain temperature is attained, time to flashover, time until a certain concentration of gases is attained, etc). Time to flashover has been used as a limit state in the Nordic countries.

3. Use knowledge of the end-use conditions and limit states to define the controlling physical and chemical mechanisms involved. Time to ignition and upward flame spread velocity are very dominant for most scenarios because they have considerable influence on both fire growth and the time to reach untenable conditions regarding toxicity.

4. Design a performance-based bench scale test method that gives as results actual or estimated flammability properties which reflect the controlling physical mechanisms involved and can be used as input for engineering methods. The Cone Calorimeter [6] can be used for this purpose.

5. Use engineering methods and simplifications in order to allow practical use of the bench-scale test results to estimate hazard in the end-use condition. A number of models of varying degrees of 
sophistication and applicability are available, both simple and more complex models are described in this paper.

\section{EARLIER MODELLING WORK ON BUILDING MATERIALS}

Much work has already been done on Points 1-5 above regarding building materials and although this paper is concerned with interior aircraft materials, we can utilize some of that work. Regarding Point 3 above, several groups of scientists, working separately in various countries, have developed flame spread theories that can be used in an engineering fashion to calculate upward flame spread and the resulting fire growth. These methods are of various degrees of sophistication and complexity. Some give approximate answers for specified end-use scenarios, can be used by others than the developers and require simple input. Other methods are more general, but may require expert knowledge and a large amount of input data.

Mainly two types of methods for such predictions, in practical end-use scenarios, have been proposed in the literature. Firstly, purely thermal models for upward flame spread have been used, with input data from the Cone Calorimeter, to predict flame spread in large scale and the resulting heat release rate. Secondly, more fundamental work has been carried out using CFD (computational fluid dynamics) models and pyrolysis models to predict fire growth.

Many different approaches to thermal modelling of flame spread have been developed, where the results have been compared to experiments involving practical building materials. All of these require that the flame morphology, specifically the flame length, be estimated as well as the heat flux from the flame to the solid materials. It is generally difficult to estimate these variables and many researchers have therefore opted for making relatively simple assumptions with respect to flame lengths and flame heat fluxes.

For example, Hasemi [7] used a variable flame heat flux to analyse temperature rise of the unburned fuel ahead of the pyrolysis front. Delichatsios [8], [9] and Beyler [10] also used expressions for a variable heat flux over the flame height to calculate the upward flame spread velocity and fire growth. A more simple approach is characterised by assuming a simple relationship between flame length and heat release rate and assuming a constant flame heat flux over this length, as Saito et al. [11] did. This led to an analytical model for upward flame spread velocity involving a Volterra-type integral. Thomas et al. [12] solved the Volterra equation and Karlsson [13] used this approach to develop a model for predicting flame spread and fire growth in several geometries, including the Room Corner test. This model requires that the material be tested in the Cone Calorimeter at a number of different heat flux levels in order to derive an apparent thermal inertia, $k \rho c$, which is then used to calculate the time to ignition. The heat release rate data from the Cone Calorimeter and the $k \rho c$ value are then used to calculate flame spread velocity and heat release rate in large-scale tests (e.g. the Room Corner test).

Several models of this type have been described in the literature and only a few will be mentioned here as examples. Cleary and Quintiere [14] developed a method that allowed both upward and lateral flame spread to be calculated, using data from the Cone Calorimeter and the LIFT apparatus. Baroudi and Kokkala [15] developed a computer program to solve the Volterra-type integral equation and Kokkala et al. [16] tested it against experiments, using Cone Calorimeter data as input.

More complex pyrolysis and flame spread models have been developed for use within CFD codes. This allows variables to be calculated locally in a very fine mesh, therefore there is no need to make the very rough assumptions on the flame height and heat flux as for the thermal models. This opens up possibilities for more sophisticated models, both for calculating solid material temperatures and mass flow rate of pyrolysis products from the solid material and the subsequent combustion. An example of such a model is given by Yan and Holmstedt [17].

The work described in this paper is to be applied to interior aircraft material. No full scale testing philosophy has been developed for fires in aircraft cabins and the materials to be used there are of a very different kind than the building materials tested earlier. We therefore seek to utilize a very simple methodology which was developed when assessing the flammability of building materials.

A simplified method assessing both the fire behaviour and toxicity of material would be a valuable step in the way polymers are studied, assessed and compared. It is a method of this kind, based on Cone 
Calorimeter measurements and supported by thermogravimetric analysis (TGA) and tube furnace measurements, which is developed in the present paper.

\section{PARAMETERS USED FOR CHARACTERISING THE FIRE PERFORMANCE OF POLYMERS}

It is generally recognized that it is desirable and cost effective to be able to assess the flammability of materials by means of small scale-tests before new formulations progress in large-scale production of products made out of these materials. We have developed a systematic way of achieving this goal [18-23] by performing experiments in micro-scale (TGA/FTIR/MDSC/ATR), meso-scale (Tube Furnace, atmospheric cone, Universal Flammability Apparatus- controlled oxidizer) and larger scale such as the SBI and ISO Room tests. Specifically, we have used the micro-scale tests to extract flammability and toxicity material properties, which through material pyrolysis and computational fluid dynamics (CFD) gaseous combustion modelling, have been applied to predict the fire behaviour in the meso-scale tests (Tube Furnace, Cone Calorimeters) and then, to predict the fire behaviour in larger scale tests such as the SBI corner and the ISO room configuration.

This method, in principle, is quantitative and accurate and thus allows the prediction on how a new material would behave in large-scale tests. However, one of the main challenges associated with this method is that it is rather time consuming in conducting all the small-scale tests and also in developing a close-to-reality physical model to describe the pyrolysis/burning of the materials in a given application. This is why, in parallel, we have developed and present here, based on the aforementioned measurements a set of fundamental parameters that can characterize and compare the flammability and toxicity of materials and differentiate their fire performance even after they have achieved the passing of a standard approval test as for example the UL-94 test [24].

We characterize the fire performance and fire toxicity of polymers using basically three and possibly five parameters based on measurements in the Cone Calorimeter at four different heat fluxes supported by thermal and gas analysis in FTIR from TGA [25]. The fist parameter is related to fire spread and growth in vertical position (simulating UL-94 and the FIGRA of SBI for instance), the second parameter is the smoke yield (simulating the SMOGRA of SBI) and the third parameter is the inefficiency of combustion (related to unburned hydrocarbon compounds and their toxicity [26]. The developed methodology and proposed parameters are applicable for charring, non-charring and intumescent materials and has been applied to all the fire retarded polymers used in the ENFIRO program (www.enfiron.eu), i.e. FR formulations based on polybutylene terephthalate (PBT) reinforced with glass fibre, nylon 66 (PA66) reinforced with glass fibre, a blend of poly(p-phenylene) ether with high impact polystyrene (PPE/HIPS) and a blend of polycarbonate with acrylonitrile butadiene styrene (PC/ABS).

Another possibly important parameter is how much of the initial material is left behind as residue. This is not significant for fire spread and fire growth but it can provide the amount of total fuel load in a fully developed fire, not relevant for the present applications.

Finally, we also propose and show that the heat release rate for thermally thin materials can be characterized by using the measurements in TGA where the maximum mass loss rate in Nitrogen (appropriately normalized by the initial mass and heating rate) is multiplied by the heat of combustion measured in the Cone Calorimeter. The derivation of these parameters is discussed in the next section.

\section{FLAMMABILITY AND TOXICITY PARAMETERS}

We are using mainly three parameters deduced from Cone Calorimeter measurements: one related to fire growth, one to smoke and one to gases toxicity. In addition as a supplement, we also can use the mass of the remaining residue and a parameter for thermally thin conditions. The derivation and explanation for each of these parameters is discussed next.

\section{Fire Growth Parameter}

The fire growth parameter is determined by the following relation, based on measurement performed in the Cone Calorimeter at an external heat flux of $50 \mathrm{~kW} / \mathrm{m}^{2}$ : 
Fire Growth Parameter $=\frac{P H R R^{2}}{t_{i g n}}$

where $P H R R^{2}$ is the square of the maximum heat release rate per unit area and $t_{i g n}$ is the ignition time.

In a previous publication [27], it was shown that this parameter is proportional to the FIGRA determined in the SBI apparatus [27]:

$F I G R A=\left(\frac{\dot{Q}_{\max }}{t_{\max }}\right)_{S B I} \propto \frac{P H R R^{2}}{t_{i g n}}$

where $\dot{Q}_{\max }$ is the maximum Heat Release Rate measured in SBI apparatus at $t_{\max }$.

Moreover, in [28], it was shown that the fire growth parameter represents a characteristic fire spread speed for materials burning in a vertical orientation for turbulent burning conditions. In this respect, we can argue that the same parameter is related to the classification of UL-94 apparatus even though the flow conditions in the UL-94 test are neither completely turbulent nor entirely laminar. The higher the value of the fire growth parameter, the more prone to flame spread the material is [27, 28].

Here, it is worthwhile to note that the present definition of the fire growth parameter is different from the one defined in $[29,30]$, where the FIGRA is defined as the ratio of PHRR to the time to peak heat release rate. This is due to the fact that cone calorimeter represents a fixed area fire whereas SBI represents a growing spreading fire.

\section{Smoke Parameter}

The second parameter is either the smoke yield, $y_{s}(\mathrm{~g} / \mathrm{g})$, or preferably the smoke yield divided by the effective heat of combustion as measured in the Cone Calorimeter as

Smoke parameter $=y_{s} / \Delta H_{c}(\mathrm{~g} / \mathrm{kJ})$

This parameter is the ratio of the amount of smoke produced divided by the heat released per gram of pyrolysing material. By using this modified smoke yield, we can observe that the product of the smoke parameter and the fire growth parameter is proportional to the SMOGRA determined by the SBI apparatus which represents the smoke production rate;

$$
S M O G R A \sim\left(\frac{P H R R^{2}}{t_{i g n}} \times \frac{y_{s}}{\Delta H_{c}}\right) \sim\left(\frac{\dot{Q}_{\max }}{t_{\max }} \times \frac{y_{s}}{\Delta H_{c}}\right)
$$

It would be more obvious to use directly the smoke yield as smoke parameter, the smoke yield being the mass of smoke produced for unit mass of burnt material. However, the amount of smoke released during a fire depends not only on the smoke yield but also on the mass pyrolysis rate. For a given heat release rate, if two materials have the same smoke yield, it is the one having the lower effective heat of combustion that releases more smoke.

Note that the carbon monoxide effects are included in the smoke parameter because the CO yield is proportional to the smoke yield, at least for over-ventilated conditions [31].

\section{Toxicity parameter}

This parameter is defined as the ratio of the effective heat of combustion of the fire retarded polymer ( $\left.\Delta H_{c, F R_{-} \text {polymer }}\right)$ to the effective heat of combustion of the neat polymer $\left(\Delta H_{c, \text { neat_polymer }}\right)$. This ratio is considered to be the efficiency of combustion. If subtracted from one, it defines the inefficiency of 
combustion. The effective heat of combustion is obtained from Cone Calorimeter measurement by dividing the total heat released by the total mass loss consumed from ignition to extinction.

Toxicity parameter $=1-\frac{\Delta H_{c, F R_{-} \text {polymer }}}{\Delta H_{c, \text { neat_polymer }}}$

When comparing pure polymer to one of its FR formulations or even when comparing two FR retarded formulations of the same base polymer, it often happens that the weight percentages of the base polymer contained in the samples are not the same. Consequently, in order to compare effective heats of combustion measured for the same amount of polymer releasing the heat, the different weight percentages of base polymer are taken into account to define the toxicity parameter as:

$1-\left(\frac{\Delta H_{C} \text { of FR formulation }}{\Delta H_{C} \text { of non } F R \text { formulation }}\right) \times \frac{\frac{w t \% \text { of polymer in non } F R \text { formulation }}{\text { Fraction of mass pyrolysed in non } F R \text { formulation }}}{\frac{\text { wt } \% \text { of polymer in } F R \text { formulation }}{\text { Fraction of mass pyrolysed in } F \text { formulation }}}(6)$

This toxicity parameter represents unburned high molecular hydrocarbon (HC), which is the main source of toxic gases different from $\mathrm{CO}$. The correlation of this parameter with toxic gases from the tube furnace is shown in [26]. Note that in this equation we consider that the polymer in the FRs pyrolyses completely for all FR containing formulations as verified by the TGA and Cone Calorimeter tests. When this toxicity parameter is greater than zero, this signifies that more of the FR polymer (compared to the base polymer) is released as unburned components including $\mathrm{CO}$ and smoke. The other unburned components (Polyaromatic hydrocarbons (PAH) and other carbon-Nitrogen compounds) are considered as toxic as verified recently in the tube furnace [26]. It is also possible that this parameter is negative, which would indicate that some FRs could actually increase the combustion efficiency of the neat polymer.

There are two other parameters described next, maybe of less importance but useful in some applications, namely mass residue and heat release parameter for burning of a material under thermally thin conditions. These quantities can be deduced from microscale TGA pyrolysis measurement in Nitrogen.

\section{Mass residue}

This parameter describes how much of the initial material is left behind as residue after combustion. This is not significant for fire spread and growth but it can provide the amount of total fuel load in a fully developed fire. This quantity can be measured in the Cone Calorimeter or in TGA in Nitrogen with experiments showing that these quantities so measured have close values [22]. Values for this parameter are not presented in this paper but are included in other publications for the materials examined in this work.

\section{Heat Release Rate for thermally thin materials}

Finally, it is straightforward to argue that the heat release rate for thermally thin materials can be characterized by using the measurements in TGA, where the maximum mass loss rate in Nitrogen (appropriately normalized by the initial mass and heating rate) is multiplied by the heat of combustion measured in the Cone Calorimeter. For thermally thin conditions (e.g. a thin sheet of the material), the material pyrolyses after ignition as the mg samples do in the TGA in Nitrogen, where thermally thin conditions (i.e. uniform heating) prevail. Therefore, we can choose to characterize the heat release rate under thermally thin burning conditions by the maximum pyrolysis rate in the TGA multiplied by the effective heat of combustion in the Cone Calorimeter normalized by the initial mass (proportional to the thickness of the material) and divided by the heating rate in the TGA, because the maximum pyrolysis rate in the TGA is nearly proportional to the heat rate. This parameter is determined by the following relation:

Heat release parameter for thermally thin conditions $=\frac{1}{m_{\text {initial }}}\left(\frac{d m}{d t}\right)_{\max } \Delta H_{c} /$ Heating rate (7) 
This parameter is similar to the parameter proposed by Lyon [32] with the difference that we use the effective heat of combustion in the Cone Calorimeter and not the total heat of combustion [32]. We also provide a different explanation for the justification of this parameter. Finally, we note that this parameter does not emulate the flame spread parameter (Eq. 1) or the heat release measured in the cone where effects of charring or intumescence are not present in the pyrolysis of the material.

\section{APPLICATION OF THE PROPOSED PARAMETERS IN COMPARING BROMINATED AGAINST HALOGEN FREE FIRE RETARDANTS (HFFRS)}

We have used the parameters in the previous section to compare and discuss the flammability and toxicity of fire retarded polymers. In all cases reported here, the fire retarded polymer formulations either by brominated or HFFRs were selected to pass the UL-94 test with rating $V-0$. First we describe the experiments and list the tested formulations and then we present the flammability and toxicity parameters.

\section{Experiments and list of formulations}

Experiments were performed in a Cone Calorimeter for sample exposed to an external heat flux of $50 \mathrm{~kW} / \mathrm{m}^{2}$. The measurements were carried out in accordance with ISO 5660 standard. In order to minimise the heat losses by conduction to insulation, a sample holder was constructed as reported by de Ris and Khan [33]. Basically, the sample was insulated with Cotronics insulation paper around its edges and behind and no retainer frame was used. In parallel, experiments of the same formulations were performed in TGA /FTIR/ATR/ tube furnace but only results from TGA at $10{ }^{\circ} \mathrm{C} / \mathrm{min}$ in Nitrogen are employed in this paper. We have established the variability (uncertainty) in our apparatus to be a number between 3$5 \%$ for individual measurements.

\section{Materials tested}

Various base polymers were tested after they were blended with halogenated or halogen free fire retardants and, sometimes, with glass fibres. Details of the formulations presented in this work are listed in Tables 1 to 5 .

Table 1. Formulations of PBT $+\mathrm{GF}$ as base polymer (weight \%).

\begin{tabular}{|c|c|c|c|c|}
\hline Compound Reference & Non FR & Brominated FR & Halogen Free+Nano & Halogen Free \\
\hline $\mathrm{PBT}+30 \%$ of GF & $100 \%$ & $85 \%$ & $82 \%$ & $85 \%$ \\
\hline Brominated polystyrene & $0 \%$ & $10 \%$ & $0 \%$ & $0 \%$ \\
\hline $\mathrm{Sb}_{2} \mathrm{O}_{3}$ & $0 \%$ & $5 \%$ & $0 \%$ & $0 \%$ \\
\hline Alpi & $0 \%$ & $0 \%$ & $15.55 \%$ & $15 \%$ \\
\hline Nano-MMT & $0 \%$ & $0 \%$ & $2.45 \%$ & $0 \%$ \\
\hline
\end{tabular}

Table 2. Formulations of PA66+GF as base polymer (weight \%).

\begin{tabular}{|c|c|c|c|c|c|}
\hline Compound Reference & Non FR & $\begin{array}{c}\text { Brominated } \\
\text { FR }\end{array}$ & $\begin{array}{c}\text { Alpi with } \\
\text { Zinc } \\
\text { Stannate }\end{array}$ & $\begin{array}{c}\text { Alpi with } \\
\text { Zinc } \\
\text { Borate }\end{array}$ & $\begin{array}{l}\text { Alpi with } \\
\text { Nano }\end{array}$ \\
\hline PA $66+30 \%$ of GF & $100 \%$ & $68 \%$ & $77 \%$ & $77 \%$ & 75 \\
\hline Brominated polystyrene & $0 \%$ & $21.3 \%$ & $0 \%$ & $0 \quad \%$ & $\%$ \\
\hline $\mathrm{Sb}_{2} \mathrm{O}_{3}$ & $0 \%$ & $10.7 \%$ & $0 \%$ & $0 \%$ & $\%$ \\
\hline Zinc Borate & $0 \%$ & $\begin{array}{ll}0 & \% \\
\end{array}$ & $0 \%$ & $3 \%$ & $\%$ \\
\hline Zinc Stannate & $0 \%$ & \begin{tabular}{ll|}
0 & $\%$ \\
\end{tabular} & $3 \%$ & $0 \%$ & $\%$ \\
\hline Alpi & $0 \%$ & \begin{tabular}{ll|}
0 & $\%$ \\
\end{tabular} & $13.3 \%$ & $13.3 \%$ & $16.67 \%$ \\
\hline MPP & $0 \%$ & $\begin{array}{ll}0 & \% \\
\end{array}$ & $6.7 \%$ & $6.7 \%$ & $8.33 \%$ \\
\hline
\end{tabular}


Table 3. Formulations of PA66 as base polymer (weight \%).

\begin{tabular}{|l|r|r|}
\hline \multicolumn{1}{|c|}{ Compound Reference } & $\begin{array}{c}\text { Without } \\
\text { FR }\end{array}$ & \multicolumn{1}{c|}{ with FR } \\
\hline PA66 (without GF) & $100 \%$ & $88 \%$ \\
\hline Melamine cyanurate & $0 \%$ & $12 \%$ \\
\hline
\end{tabular}

Table 4. Formulations of PPE/HIPS as base polymer (weight \%).

\begin{tabular}{|l|r|r|r|}
\hline \multicolumn{1}{|c|}{ Compound Reference } & Non FR & $\begin{array}{c}\text { Brominated } \\
\text { FR }\end{array}$ & $\begin{array}{c}\text { Halogen } \\
\text { free FR }\end{array}$ \\
\hline $\mathrm{PPE}+\mathrm{HIPS}$ & $100 \%$ & $80 \%$ & $85 \%$ \\
\hline $\mathrm{DecaBDE}$ & $0 \%$ & $14 \%$ & $0 \%$ \\
\hline $\mathrm{Sb}_{2} \mathrm{O}_{3}$ & $0 \%$ & $6 \%$ & $0 \%$ \\
\hline $\mathrm{RDP}$ & $0 \%$ & $0 \%$ & $15 \%$ \\
\hline
\end{tabular}

Table 5. Formulations of PC/ABS as base polymer (weight \%).

\begin{tabular}{|l|r|r|r|r|}
\hline \multicolumn{1}{|c|}{ Compound Reference } & Non FR & $\begin{array}{c}\text { Brominated } \\
\text { FR (Deca) }\end{array}$ & $\begin{array}{c}\text { Brominated } \\
\text { FR } \\
\text { (TBBPA) }\end{array}$ & \multicolumn{1}{c|}{$\begin{array}{c}\text { Halogen } \\
\text { free FR }\end{array}$} \\
\hline $\mathrm{PC}+\mathrm{ABS}$ & $100 \%$ & $83 \%$ & $83 \%$ & $77 \%$ \\
\hline $\mathrm{DecaBDE}$ & $0 \%$ & $10 \%$ & $0 \%$ & $0 \%$ \\
\hline $\mathrm{TBBPA}$ & $0 \%$ & $0 \%$ & $10 \%$ & $0 \%$ \\
\hline $\mathrm{Sb}_{2} \mathrm{O}_{3}$ & $0 \%$ & $5 \%$ & $5 \%$ & $0 \%$ \\
\hline $\mathrm{RDP}$ & $0 \%$ & $0 \%$ & $0 \%$ & $20 \%$ \\
\hline $\mathrm{PTFE}$ & $0 \%$ & $2 \%$ & $2 \%$ & $3 \%$ \\
\hline
\end{tabular}

\section{RESULTS AND DISCUSSION}

We repeat here that all fire retarded formulations have passed the UL-94 test with a rating V-0. The use of the present approach (or more detailed numerical modelling [23,34]) allows to differentiate the performance of these formulation with respect to flammability and toxicity beyond the blank statement of V-0 from UL-94.

\section{Fire growth and smoke parameters}

Figure 1a is a plot of the flame spread parameter (Eq. 1) and the smoke yield (Eq. 2), whereas Fig. 1b is the same data but the smoke yield $\left(y_{s}\right)$ is replaced by the smoke parameter $\left(y_{s} / \Delta H_{c}\right.$, Eq. 3$)$. The advantage of the second presentation in Fig. 1b is that the product of the coordinates is proportional to the smoke production rate, which can be used as another criterion for relative comparison of FRs. Obviously, a good formulation as indicated in the figures should have low values of both fire growth and smoke parameters. Considering all the materials, it is clear that all neat polymers have the highest fire growth parameter, i.e., higher heat release rates (HRRs) and lower times to ignition (TTIs), though having the lowest smoke yield. The BrFRs, generally reduce the fire growth parameter considerably (note that the ordinate is in logarithm) by decreasing the HRR while increasing the TTI; however they also increase significantly the smoke yield as expected because they mainly act in the gaseous phase by inhibiting combustion (i.e., reducing combustion efficiency). The HFFRs, on the other hand, have similar or lower fire growth parameters in comparison to BrFRs but with smaller smoke yields. This is due to the fact that the HFFRs mostly acted in the solid phase by forming a surface (intumescent) layer at the top of virgin material or enhancing the strength and integrity of the char formed by other components such as glass fibres or nanoclays. It is worth noting that the behaviour is similar not only for the fire growth parameter but also for the HRR and ignition (in general). The more specific information including the mass loss rate is used to produce flammability properties for detailed modelling as in [34]. 


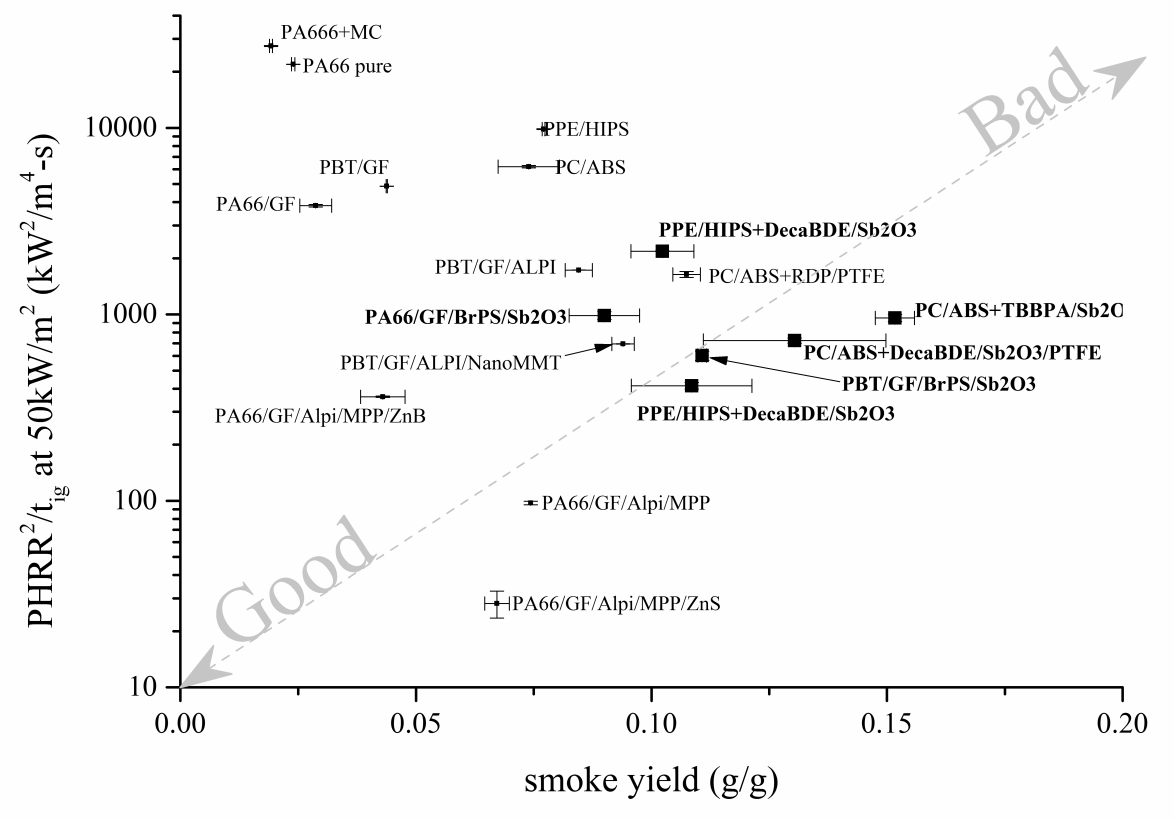

Fig. 1a. Comparison of various polymers based on Fire Growth Parameter and Smoke yield. Brominated samples are bolded.

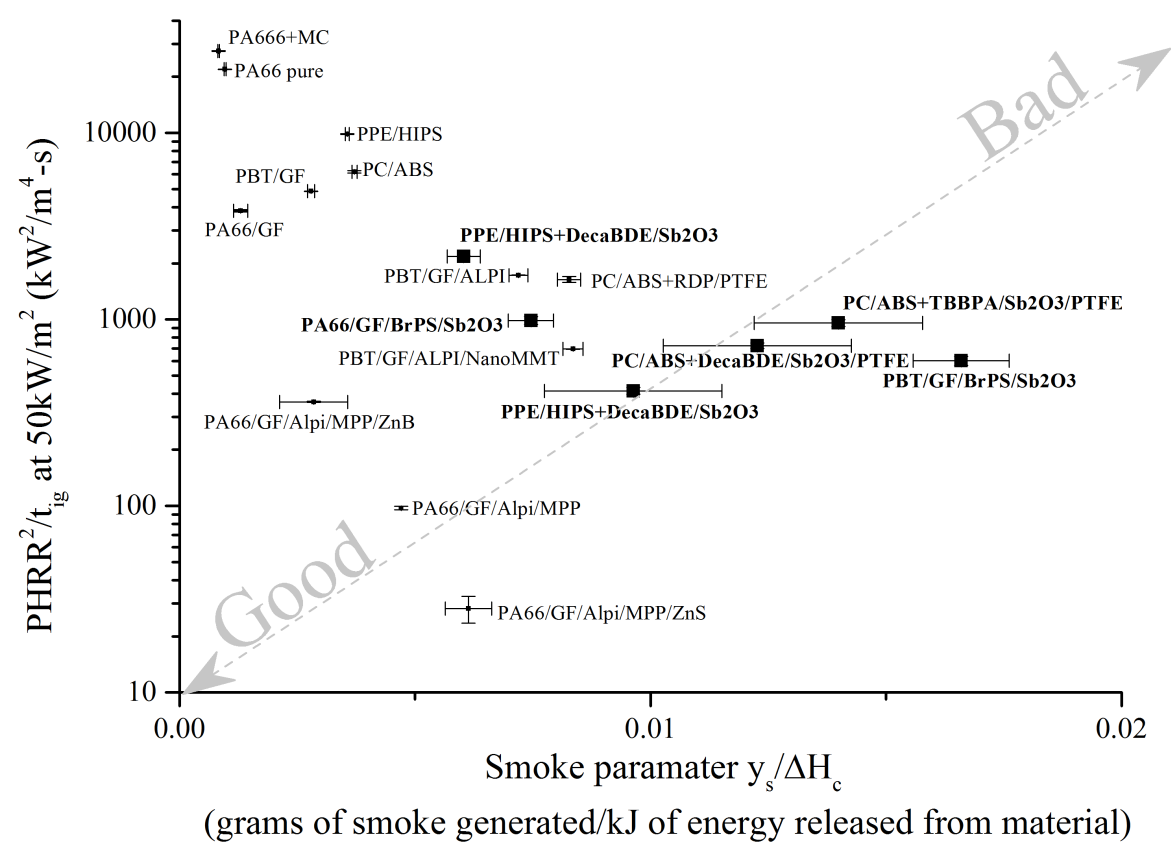

Fig. 1b. Comparison of various polymers based on Fire Growth Parameter and Smoke parameter. Brominated samples are bolded. 


\section{Toxicity parameter}

Figures 2-5 show the toxicity of various formulations in comparison to the neat polymers based on the toxicity parameter (Eqs. 5 and 6). It is worth recalling that this parameter represents the combustion inefficiency of fire retarded formulations, so it is zero for all neat polymers. It can be observed that all BrFRs formulations have the highest toxicity parameter, indicating reduced heat of combustion in the presence of BrFRs. Figure 2 also shows the synergistic effect of the HFFR and nanoclay because the formulation containing both achieves higher combustion efficiency than the formulation containing HFFR alone. Moreover, it is observed in Fig. 3 that for PA6+GF based formulations the toxic parameter is negative for all formulations containing HFFRs, which indicates that combustion efficiency may be higher than that of pure polymer owing to the presence of extra oxygen in the HFFRs.

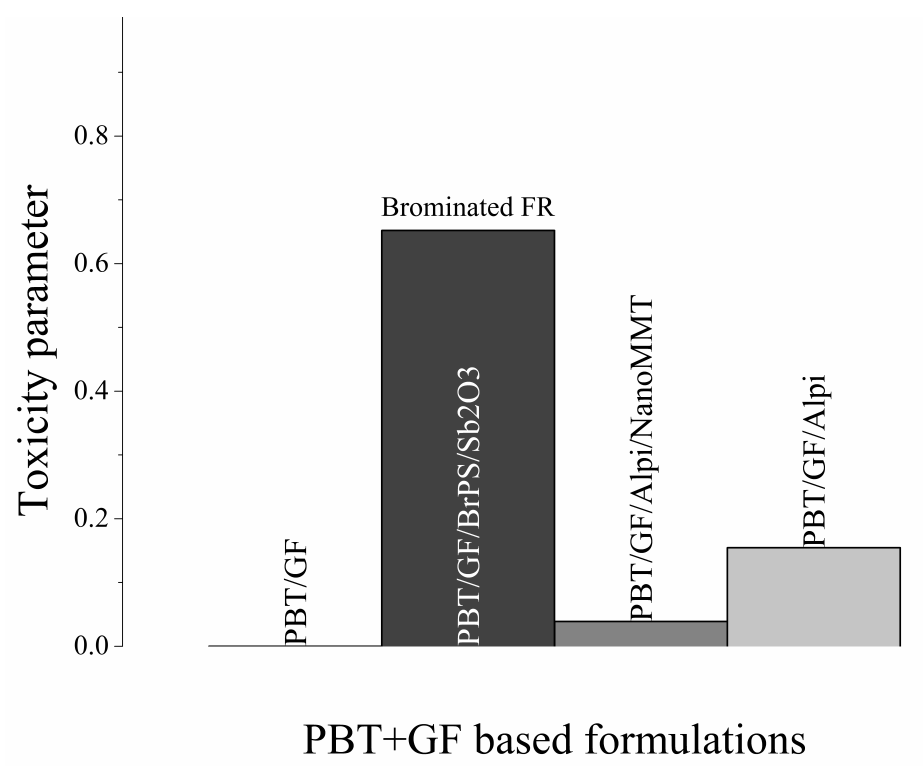

Fig. 2. Toxicity assessment of PBT formulations based on effective heat of combustion from cone calorimeter

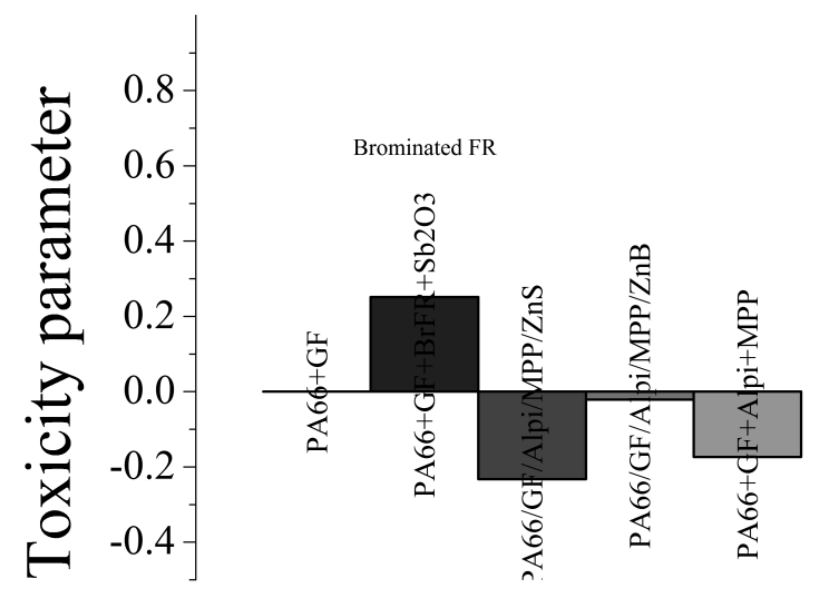

PA6+GF based formulations

Fig. 3. Toxicity assessment of PA66 formulations 


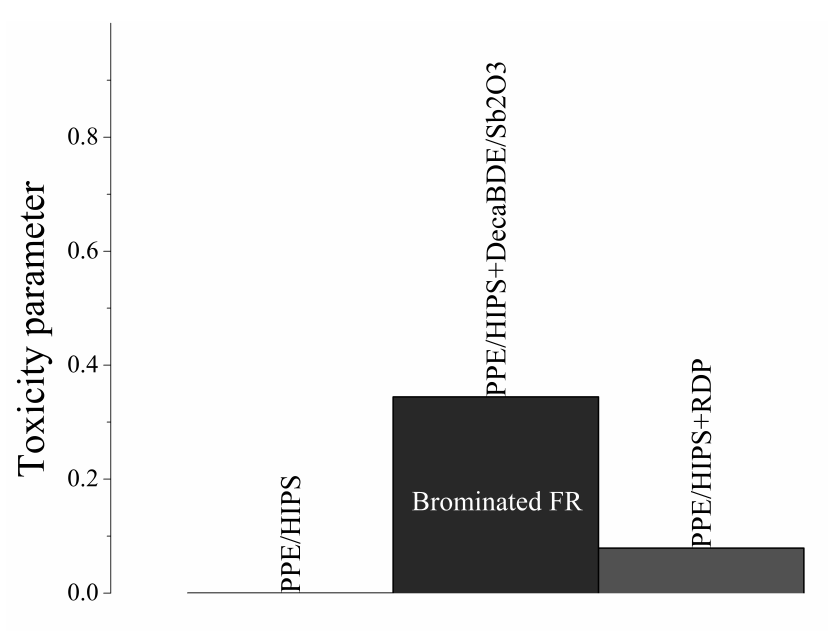

PPE/HIPS based formulations

Fig. 4. Toxicity assessment of PPE/HIPS formulations

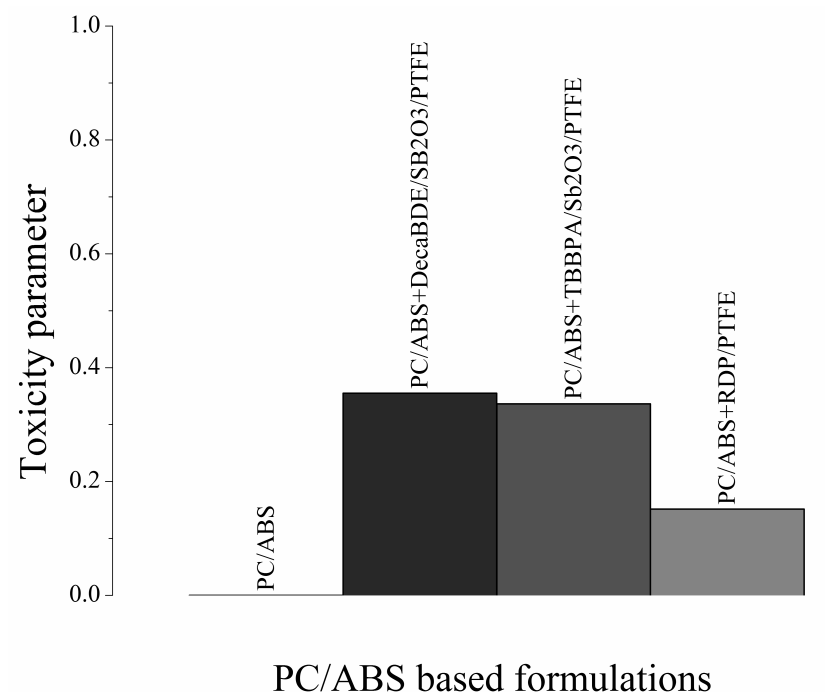

Fig. 5. Toxicity assessment of PC/ABS formulations

\section{Heat Release Rate for thermally thin materials}

Figures $6 \mathrm{a}$ and $6 \mathrm{~b}$ present respectively the heat release parameter for thermally thin conditions for PBT and PA66 based formulations (Eq. 7). It should be noted that this parameter does not account for the effects of char in reducing the mass loss rate as observed in the Cone Calorimeter, because the $\mathrm{mg}$ samples are used in TGA.

It is interesting to notice that for PBT based formulation the brominated PBT $+\mathrm{GF}$ (PG2) attains the smallest value, which is opposite to the measurements in the Cone Calorimeter, where thermally thick conditions prevail. In this case, the phosphorous and nano formulations induce much less mass loss rate owing to the formation of a char layer in the solid phase in addition to the GF effect.

In contrast, Fig. $6 \mathrm{~b}$ shows that the PA66 formulation containing BrFR has a higher value than neat PA66+GF. This is due to the fact that brominated PA66+GF has a maximum mass loss rate in the TGA about twice that of neat PA66+GF, even though it has smaller heat of combustion. 


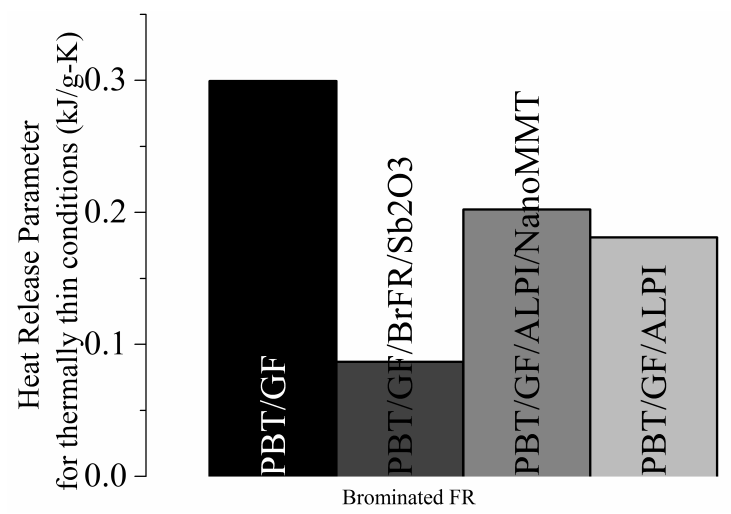

Fig. 6a. Heat release parameter for PBT formulations for thermally thin conditions calculated as $\frac{\left(\frac{1}{\boldsymbol{m}_{\text {initial }}} \times \boldsymbol{m a x} \frac{\partial \boldsymbol{m}}{\partial t}\right)}{\text { heating rate }} \times \Delta \boldsymbol{H}_{\text {eff }}$, where $\boldsymbol{m}_{\text {initial }}$ is initial mass of sample $(\mathrm{mg}), \boldsymbol{m a x} \frac{\boldsymbol{\partial} \boldsymbol{m}}{\partial \boldsymbol{t}}$ is peak mass loss rate $(\mathrm{mg} / \mathrm{s})$ and $\Delta \boldsymbol{H}_{\boldsymbol{e f f}}$ is effective heat of combustion $(\mathrm{kJ} / \mathrm{g})$ taken from Cone calorimeter

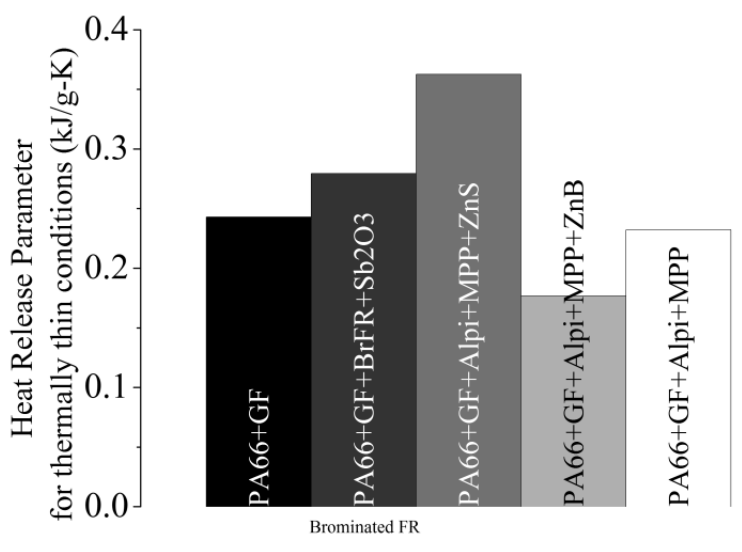

Fig. 6b. Heat release parameter for PA66 formulations for thermally thin conditions

\section{CONCLUSIONS}

This paper presents a novel method to assess the fire growth, smoke production and toxicity of BrFRs and HFFRs based on the three and possibly five parameters measured from TGA and Cone Calorimeter, namely fire growth parameter, smoke parameter, toxicity parameter, mass residue and heat release rate for thermally thin conditions. These parameters allow the differentiation of the fire performance of various fire retardants, which cannot be achieved by standard industrial tests such as UL-94 that does not allow any differentiation of material behaviour inside a given rank. The method was applied to four base polymers modified with both BrFRs and HFFRs. The main conclusions of this study are:

- The fire growth and smoke parameters show that (i) base polymers have the highest fire growth parameter but with minimum production of smoke, (ii) BrFRs reduce the fire growth parameter but increase the smoke production considerably and (iii) HFFRs achieve similar and smaller fire growth parameter but with less smoke production compared to BrFRs.

- The toxicity parameter shows that BrFRs have highest inefficiency of combustion because of their strong gaseous action, whereas HFFRs have higher combustion efficiency because they mostly act in the solid phase by modifying the char formed on the surface of the polymer.

- Finally, the heat release rates at thermally thin conditions show different behaviours between $\mathrm{PBT}+\mathrm{GF}$ and PA66+GF formulations, where the formulation containing BrFRs has the lowest value for $\mathrm{PBT}+\mathrm{GF}$ whilst the highest for PA66+GF. The opposite behaviour by PA66+GF is due to the fact 
that brominated PA66+GF has a maximum mass loss rate about twice that of neat PA66+GF. This result demonstrates the limitation of TGA data which is obtained under thermally thin condition as opposed to real burning conditions where the material behaves as a thermally thick material as typically found in the Cone Calorimeter tests.

\section{ACKNOWLEGEMENTS}

The authors acknowledge the EU for financially supporting the ENFIRO project under Grant No 226563 and AircraftFire Project under Grant No 265612. The authors also thank Mr M McKee and W Veighey for helping with the Cone experiments.

\section{REFERENCES}

[1] ISO International Organization for Standardization 2006-10-15 \#1

[2] CIB "Working with the Performance Approach in Building", CIB Report 64, 1982.

[3] CIB International workshop on new developments in performance based test methods, Proceedings publication 179, CIB, 1996.

[4] Karlsson B and Kokkala M, "New developments in performance based test methods for fire safety assessment of products", International workshop on new developments in performance based test methods, Proceedings publication 179, CIB, 1996.

[5] ISO 9705:1993 Fire tests -- Full-scale room test for surface products, International Standards Organisation, 1993.

[6] ISO 5660-1:1993 Fire tests -- Reaction to fire -- Part 1: Rate of heat release from building products -- (Cone calorimeter method), International Standards Organisation, 1993.

[7] Hasemi Y, "Thermal modeling of upward wall flame spread, Fire Safety Science, Proceedings of the First International Symposium, Hemishpere Pub. Co., 1986.

[8] Delichatsios M M, Mathews, M K and Delichatsios M A, "An upward flame spread and growth simulation" Fire Safety Science, Proceedings of the Third International Symposium, Elsevier Science Publishers Ltd., 1991.

[9] Delichatsios M A, "Critical Conditions for Upward Flame Spread and Comparison with Empirical Flammability Indices", Combust. Sci. and Tech., 106, 125, 1995.

[10] Beyler C L, Hunt S P, Ibqal N and Williams F W, "A computer model of upward flame spread on vertical surfaces", Fire Safety Science, Proceedings of the Fifth International Symposium, Melbourne, 1997.

[11] Saito K, Quintiere J G and Williams F A, "Upward Turbulent Flame Spread" Fire Safety Science, Proceedings of the First International Symposium, Hemisphere Pub. Co., 1986.

[12] Thomas P H and Karlsson B, "On Upward Flame Spread on Thick Fuels”, SE-LUTVDG/TVBB3058, Department of Fire Safety Engineering, Lund University, 1990.

[13] Karlsson B, "Modelling Fire Growth on Combustible Lining Materials in Enclosures", Report TVBB 1009, Department of Fire Safety Engineering, Lund University, 1992.

[14] Cleary T and Quintiere J G, "A framework for utilizing fire property tests", Fire Safety Science, Proceedings of the Third International Symposium, Elsevier Science Publishers Ltd., 1991.

[15] Baroudi D and Kokkala M, "Analysis of Upward Flame Spread", VTT Publications 89, VTT, Espoo, Finland 1992.

[16] Kokkala M and Baroudi D, "Upward Flame Spread and Heat Release Rate of Wood Products: Experiments and Numerical Modelling", Fire Safety Science, Proceedings of the Fifth International Symposium, Melbourne, 1997. 
[17] Yan Z and Holmstedt G, "CFD and Experimental Studies of Room Fire Growth on Wall Lining Materials”, Fire Safety Journal, Vol. 27 201-238, 1996.

[18] Zhang, J., Delichatsios, M., and S. Bourbigot, Experimental and numerical study of the effects of nanoparticles on pyrolysis of a polyamide 6 (PA6) nanocomposite in the Cone Calorimeter, Combustion and Flame, 156(11):2056-62, 2009

[19] Zhang, J., Delichatsios, Further validation of a numerical model for prediction of pyrolysis of polymer nanocomposites in the Cone Calorimeter, Fire Technology, 46: 307-319, 2010

[20] The Single Burning Item (SBI) test, EN. 13823.

[21] Zhang, J., Delichatsios, Assessment of Fire Dynamics Simulator for Heat Flux and Flame Heights Predictions from Fires in SBI Tests, Fire Technology, 46: 291-306, 2010

[22] Zhang, Jianping, Delichatsios, Michael, McKee, Maurice and Ukleja, Sebastian Experimental and numerical study of burning behaviours of flaxboard with intumescent coating and nanoparticles in the Cone Calorimeter and single burning item tests. Fire and Materials, 36 (7). pp. 554-564, 2012

[23] Delichatsios, Michael and Zhang, Jianping, Micro- to Mesoscale Testing and Modeling for Nanocomposite polymers in Fires, in Fire Retardancy of Polymeric Materials, Second Edition, edited by C Wilkie and A Morgan, 2010

[24] UL-94, the Standard for Safety of Flammability of Plastic Materials for Parts in Devices and Appliances testing, ISO 9773

[25] Delichatsios, M., Ramani, A., Zhang, J. Suzanne, M., Ukleja, S., and Bakirtzis, D., "Fire Assessment of Brominated and Halogen Free Flame Retardants in Polymers Using TGA-FTIRATR and Cone Residue-ATR", Proceedings of 13th International Conference and Exhibition on Fire Science and Engineering, 2013.

[26] Ukleja, S., Delichatsios, M., Suzanne, M., "Comparison of toxicity from tube furnace with toxicity/inefficiency of combustion from Cone calorimeter for halogen free and halogenated fire retarded polymers" , Proceedings of $5^{\text {th }}$ International Seminar on Modern Polymeric Materials for Environmental Applications, 2013.

[27] Delichatsios, M. , Application of upward flame spread for the Prediction of SBI and ISO room corner (and parallel wall) experiments and classification, Thermal Science, 11 , 2, pp. 7-22, 2007.

[28] Delichatsios, M. Critical conditions for upward flame spread and comparison with empirical flammability indices, Combust. Sci. and Techn. ,106, 125-136,1995.

[29] Shonali Nazare, Baljinder Kandola and A. Richard Horrocks. Fire Mater. 2002; 26: 191-199.

[30] Björn Sundström. The Development of a European Fire Classification System for Building Products. 2005.

[31] Tewarson, A ., Smoke Emissions In Fires, Fire safety science-proceedings of the ninth international symposium, pp. 1153-1164, 2008.

[32] Lyon , R .E. and Walters , R., A Microscale Combustion Calorimeter, DOT/FAA/AR-01/117, 2002.

[33] J.L. de Ris, M.M. Khan, A sample holder for determining material properties, Fire Mater., 24 (2000), pp. 219-226

[34] Mathieu Suzanne, Alwar Ramani, Sebastian Ukleja, Maurice Mckee, Jianping Zhang \& Michael Delichatsios, Experimental and Numerical Study of Thermal Stability and Fire Performance of Brominated and Halogen-free Flame Retardants in Glass-fibre Reinforced Poly(butylene terephthalate), 11th International Symposium on Fire Safety Science, accepted. 